\title{
Research on Management Strategy of Network Public Sentiment in Chinese Universities
}

\author{
Jin WEN ${ }^{*}$ \\ Department of humanities and management, JiangXi Police College, NanChang, China \\ *Corresponding author
}

Keywords: Management strategy, Internet, Public sentiment, University.

\begin{abstract}
With the rapid development of Internet information technology, the position and role of network public opinion in the work of security and stability in Colleges and universities is becoming more and more prominent. When the network public opinion occurs in universities, the result of university management department's handling of Internet public opinion has become an important aspect of measuring the University's administrative ability. Therefore, the improvement of public opinion processing ability is of great significance for the maintenance of school image and the protection of students' interests. This paper takes the principles and Strategies of Chinese universities to deal with internet public opinion as the research objects, and puts forward measures such as strengthening public opinion detection, timely releasing information, timely handling and improving system construction, so as to enhance the public opinion ability of university management departments.
\end{abstract}

\section{Introduction}

With the rapid development of Internet and other information technology, more and more Chinese college students express their ideas through forum, news, blog and other channels. Internet public opinion has become an important vane to reflect social public sentiment. Therefore, Internet forums and other natural universities have become the network platform for college students' free comment. Great news and emergencies inside and outside campus will arouse wide attention and Discussion on this platform.

As the main force of the network of college students, because of similar age, experience and habits similar, so it has high degree of homogeneity and their values are more easy to reach agreement to produce emotional resonance, thus forming a group consensus. Nowadays, with the relative lag of network legislation and network education management, social public morality is often lacking in moral constraints on individuals, which makes it difficult to control network public opinion. Internet public opinion in Colleges and universities is a weathervane and barometer reflecting the ideological trend of college teachers and students. It mainly expresses related events or problems through news network, student websites, forums, blogs and QQ. The network public opinion mainly in the following categories: one is related to social stability of speech of teachers and students of major domestic and international hot issues, relevant countries, national emotion and other sensitive issues; two is the public opinion information related to school running their own image and reputation; three is the incident involving the staff and students and campus security environment information; four students of the school teaching, reform, enrollment, examination and other related work of opinions and suggestions.

\section{Design and Statistics of Questionnaire}

The questionnaire is divided into two parts. The first part is the definition of the basic concepts involved in the questionnaire and the collection of the basic information of the respondents, so that both the investigated and the investigated parties have a preliminary understanding of each other, making it easier for further information communication. The second part is the specific content of the research. There are two kinds of questions: indefinite choice and open question. Its contents 
include the types of major events that college students are concerned about and the opinion and evaluation of university public opinion governance.

In order to ensure the reliability and validity of the questionnaire, and to present the status quo more comprehensively and objectively, the stratified sampling method was adopted in this research. Due to the various elements of professional education and other possible overlap in the course of the investigation, in order to avoid duplication and confusion in the sample, and there is no specific restrictions for digital objects at different levels in the process of sampling, but the awareness questionnaire in keeping the balance between academic and professional. At the same time, in order to make the results of the survey more authentic and universal, some sample interviews were conducted on the basis of the questionnaire survey. The basic statistics of this study are shown in Table 1.

Table 1. Sample basic statistics

\begin{tabular}{|c|c|c|c|}
\hline Variable & Value & Amount & Ratio \\
\hline \multirow{2}{*}{ Gender } & Male & 75 & $75 \%$ \\
\hline & Female & 25 & $25 \%$ \\
\hline \multirow{2}{*}{ Major } & Social sciences & 82 & $82 \%$ \\
\hline & Natural science & 18 & $18 \%$ \\
\hline \multirow{2}{*}{ Political status } & Party member & 90 & $90 \%$ \\
\hline & Public people & 10 & $10 \%$ \\
\hline \multirow{4}{*}{ Grade } & First grade & 22 & $22 \%$ \\
\hline & Second grade & 25 & $25 \%$ \\
\hline & Third grade & 25 & $25 \%$ \\
\hline & Fourth grade & 28 & $28 \%$ \\
\hline
\end{tabular}

The proportion of male Internet public events is $75 \%$, while female students are $25 \%$. Male students have higher public interest and participation enthusiasm than female students. The subject of public opinion in social science study accounted for $82 \%$, slightly higher than in natural learning students. In the grade distribution, in flat state, indicates that the subject of public opinion and the professional grade has little influence on the.

The Internet public opinion group has certain knowledge and skills, and has high political enthusiasm. Their participation in the network is a reflection of cultivating political sense of mission and national responsibility. The statistics of the participation of network public opinion groups in higher institutions are shown in Table 2.

Table 2. The participation of network public opinion groups in Colleges and Universities

\begin{tabular}{|c|c|c|c|}
\hline Variable & Value & Amount & Ratio \\
\hline \multirow{3}{*}{ Online reviews } & $\mathrm{Y}$ & 45 & $45 \%$ \\
\cline { 2 - 4 } & $\mathrm{N}$ & 55 & $55 \%$ \\
\hline \multirow{3}{*}{ Client } & Mobile phone & 85 & $85 \%$ \\
\hline \multirow{4}{*}{ Topic } & Computer & 90 & $90 \%$ \\
\cline { 2 - 4 } & Economic development & 84 & $84 \%$ \\
\cline { 2 - 4 } & Government reform & 92 & $92 \%$ \\
\cline { 2 - 4 } & Obtain employment & 90 & $90 \%$ \\
\cline { 2 - 4 } & Recreation \& Entertainment & 75 & $75 \%$ \\
\cline { 2 - 4 } & Education & 35 & $35 \%$ \\
\hline \multirow{3}{*}{ Daily Internet time } & Other & 45 & $45 \%$ \\
\cline { 2 - 4 } & Less than 1 hours & 21 & $21 \%$ \\
\cline { 2 - 4 } & Motween 1 and 8 hours & 70 & $70 \%$ \\
\hline
\end{tabular}

The survey shows that the group of Internet public opinion in Colleges and universities identify independent participation in the network discussion, accounting for $45 \%$, but it does not exclude the 
participation of the common network. The topic of public opinion in Colleges and universities focuses more on government reform and employment, reaching 92\% and 90\% respectively, which indicates that the participation behavior of college new opinion group is positively related to political efficacy to some extent. From the survey we can see that the Internet was open college students' political participation channels, activate their enthusiasm for political participation, showing a strong sense of political efficacy, so as to inject a new vitality for the network construction of democracy, can make the university network public opinion in the right direction.

In addition, according to a survey of college network public opinion management policy group, $84.3 \%$ of the people concerned about the school, $91.3 \%$ people are concerned about the hot issues of the school, 88.4\% people are concerned about the common aspirations of their population, $71.4 \%$ of those concerns are closely related to their own interests and student group events.

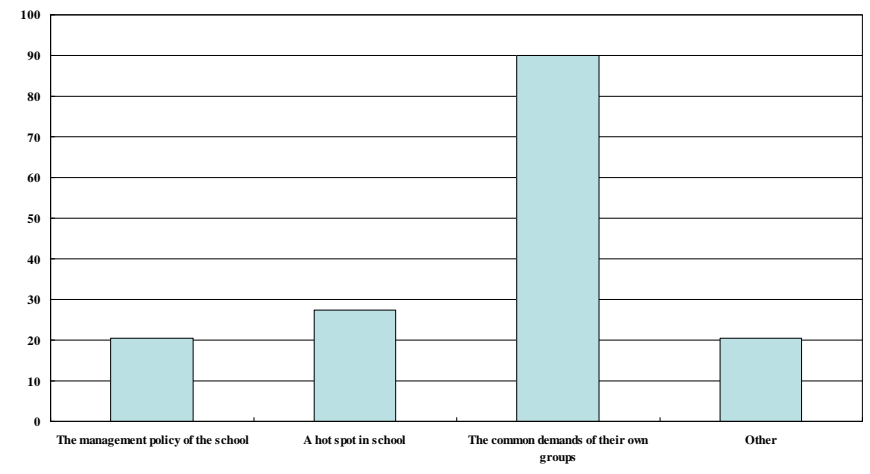

Figure 1. College students pay attention to hot spots

\section{Strategy Analysis of Network Public Sentiment}

Based on the idea and method of big data, data collection, mining and analysis of network public opinion in Colleges and universities can greatly improve the discovery power and guidance ability of university network public opinion, and enhance the effectiveness of college internet public opinion. Make timely analysis and emergency response to public opinion may have a negative impact, especially relates to social stability and security on campus, the school's reputation and reputation of the staff and students' rights and privacy and involving pornography network public opinion, to take immediate measures to remove or sealed, maintenance network order. It is necessary to strengthen the management of the users of the campus network and implement the real name registration so as to verify the ground when necessary.

We should improve network monitoring and early warning capabilities through technological innovation, develop real-time monitoring and tracking software for network public opinion information, further establish and improve network security protection, information filtering and other systems, and build a campus network security technology prevention and control system.

The network public opinion groups of colleges and universities have strong sense of responsibility of their times, lively comments on many issues, colleges and universities must fully understand the negative impact from the network media era of public opinion, to seize the main battlefield of public opinion, the effectiveness of the strategy of actively looking for governance of network public opinion, education and guidance of college students of public opinion.

First, use big data to find network hotspots in time and predict network public opinion. In the era of big data, by collecting large amounts of data, including the public opinion dissemination carrier category, scope and scale of interaction and whether there is a network of celebrities and other related data, and then by means of computing model and algorithm, it can successfully predict the future information dissemination of heat, greatly enhance the accuracy of pre university administrators to network public opinion.

Second, use big data to accurately judge the false public sentiment. Due to the differences in the ability and level of Internet public opinion administrators, the individual individual's judgments on university public opinion are also different, which will seriously affect the decision-making of 
universities. Big data information provides first-hand materials based on the integrity, accuracy and speed of the whole network, so that the analysis of University online public opinion based on big data can accurately reflect the actual situation of universities.

Third, using large data to accurately excavate University contradictions and understand the social mentality. In the traditional network public opinion monitoring, the collection of public opinion related data is only sample information, the data structure is single, and the amount of data is limited. The big data can record the actual situation of university more comprehensively, completely present the psychological change of college students, and can understand the social mentality behind the public opinion accurately.

\section{Discussion and Future Work}

With the development and popularization of the network, the network of public opinion as a part of life in the network, change the lifestyle of college students play a certain role in promoting. University management departments must be fully aware of the negative impact from the network media era of public opinion, to seize the main battlefield of public opinion, the effectiveness of the strategy of actively looking for governance of network public opinion.

\section{Acknowledgment}

This author’s work is supported by JiangXi Police College Scientific Research Project.

\section{References}

[1] Guo Guanghua. On the tendency of group polarization of the main body of network public opinion[J]. Journal of Social Sciences of Hunan Normal University, 2004, (6).

[2] Guo Jianqiang. The era of big data network public opinion management reform[J]. Guangxi Social Sciences, 2015, (9).

[3] Pu Qingping. Research on the security management of network ideology based on large data[J]. School Party Building and Thought Research, 2017, (10).

[4] Chen Long. Construction and application of evaluation index system for public opinion intensity in Colleges and universities [J]. Modern Information, 2014, 34 (09): 65-70.

[5] Gao Jun. Research on response to public opinion misunderstanding and Countermeasures in the new media era[J]. Jiangsu Higher Education, 2014 (05): 55-56. 